\title{
Pathophysiology of primary spinal syringomyelia
}

\author{
Clinical article
}

\author{
John D. Heiss, M.D., ${ }^{1}$ Kendall Snyder, B.A., ${ }^{2}$ Matthew M. Peterson, M.D., ${ }^{3}$ \\ Nicholas J. Patronas, M.D. ${ }^{4}$ John A. Butman, M.D., Ph.D., ${ }^{4}$ René K. Smith, B.S.N., ${ }^{1}$ \\ Hetty L. DeVroom, B.S.N., ${ }^{1}$ Charles A. Sansur, M.D., ${ }^{5}$ Eric Eskioglu, M.D., ${ }^{6}$ \\ William A. Kammerer, M.D. ${ }^{7}$ and Edward H. OLdfield, M.D. ${ }^{8}$
}

${ }^{1}$ National Institute of Neurological Disorders and Stroke, Surgical Neurology Branch, ${ }^{4}$ Clinical Radiology, and ${ }^{7}$ Department of Anesthesia, National Institutes of Health, Bethesda, Maryland; ${ }^{2}$ George Washington University School of Medicine, Washington, DC; ${ }^{3}$ Tulane University School of Medicine, New Orleans, Louisiana; ${ }^{5}$ Department of Neurosurgery, University of Maryland, Baltimore, Maryland; ${ }^{\circ}$ NeuroVascular and Stroke Institute, Physicians Regional Healthcare System, Naples, Florida; and ${ }^{8}$ Department of Neurological Surgery, University of Virginia Health System, Charlottesville, Virginia

Object. The pathogenesis of syringomyelia in patients with an associated spinal lesion is incompletely understood. The authors hypothesized that in primary spinal syringomyelia, a subarachnoid block effectively shortens the length of the spinal subarachnoid space (SAS), reducing compliance and the ability of the spinal theca to dampen the subarachnoid CSF pressure waves produced by brain expansion during cardiac systole. This creates exaggerated spinal subarachnoid pressure waves during every heartbeat that act on the spinal cord above the block to drive CSF into the spinal cord and create a syrinx. After a syrinx is formed, enlarged subarachnoid pressure waves compress the external surface of the spinal cord, propel the syrinx fluid, and promote syrinx progression.

Methods. To elucidate the pathophysiology, the authors prospectively studied 36 adult patients with spinal lesions obstructing the spinal SAS. Testing before surgery included clinical examination; evaluation of anatomy on T1weighted MRI; measurement of lumbar and cervical subarachnoid mean and pulse pressures at rest, during Valsalva maneuver, during jugular compression, and after removal of CSF (CSF compliance measurement); and evaluation with CT myelography. During surgery, pressure measurements from the SAS above the level of the lesion and the lumbar intrathecal space below the lesion were obtained, and cardiac-gated ultrasonography was performed. One week after surgery, CT myelography was repeated. Three months after surgery, clinical examination, T1-weighted MRI, and CSF pressure recordings (cervical and lumbar) were repeated. Clinical examination and MRI studies were repeated annually thereafter. Findings in patients were compared with those obtained in a group of 18 healthy individuals who had already undergone T1-weighted MRI, cine MRI, and cervical and lumbar subarachnoid pressure testing.

Results. In syringomyelia patients compared with healthy volunteers, cervical subarachnoid pulse pressure was increased $(2.7 \pm 1.2$ vs $1.6 \pm 0.6 \mathrm{~mm} \mathrm{Hg}$, respectively; $\mathrm{p}=0.004)$, pressure transmission to the thecal sac below the block was reduced, and spinal CSF compliance was decreased. Intraoperative ultrasonography confirmed that pulse pressure waves compressed the outer surface of the spinal cord superior to regions of obstruction of the subarachnoid space.

Conclusions. These findings are consistent with the theory that a spinal subarachnoid block increases spinal subarachnoid pulse pressure above the block, producing a pressure differential across the obstructed segment of the SAS, which results in syrinx formation and progression. These findings are similar to the results of the authors' previous studies that examined the pathophysiology of syringomyelia associated with obstruction of the SAS at the foramen magnum in the Chiari Type I malformation and indicate that a common mechanism, rather than different, separate mechanisms, underlies syrinx formation in these two entities. Clinical trial registration no.: NCT00011245. (http://thejns.org/doi/abs/10.3171/2012.8.SPINE111059)

\section{KEY WORDS • syringomyelia • physiology • ultrasonography surgery • cerebrospinal fluid • magnetic resonance imaging • myelography}

$\mathrm{S}$ YRINGOMYELIA associated with spinal pathology is known as primary spinal syringomyelia (PSS).,3 The natural history of this and other forms of syrin-

Abbreviations used in this paper: ASIA = American Spinal Injury Association; PSS = primary spinal syringomyelia; SAS = spinal subarachnoid space. gomyelia is one of gradual, stepwise deterioration over many years.,73 Primary spinal syringomyelia, which accounts for about one-sixth of all cases of syringomyelia, may be a consequence of traumatic injury, inflammatory conditions, or compressive lesions that compromise the subarachnoid space..$^{71}$ Posttraumatic syringomyelia manifests as progressive neurological deficit above the level of 
previous spinal cord injury that begins several months to years after initial trauma. ${ }^{13,20,31,32,51,57,60,62,71}$ The incidence of syringomyelia following trauma that produces paraplegia was previously estimated to be $1 \%-4 \%$, although with the availability of MRI the incidence appears to be much higher. ${ }^{18}$ Postinflammatory syringomyelia results from a delayed reaction to meningitis, either infectious or chemical. 6,15,16,29,52,65 Syringomyelia also occurs in association with compression of the CSF pathways by extramedullary tumors, osteophytes, or herniated intervertebral discs. ${ }^{1,7-9,25,28,41,42,46,55,69,74}$ In contrast, when syringomyelia is associated with an intramedullary tumor, the CSF pathways are usually not obstructed, and syrinx fluid is thought to arise from the tumor. ${ }^{40}$ Syrinx fluid in PSS is identical to CSF, whereas syrinx fluid in syringomyelia associated with an intramedullary tumor is highly proteinaceous. ${ }^{9,21,38,49}$

We previously reported the results of physiological studies that support the theory that progression of syringomyelia associated with the Chiari Type I malformation is produced by the cerebellar tonsils partially occluding the subarachnoid space at the foramen magnum and acting as a piston on the partially enclosed SAS, creating enlarged cervical subarachnoid pressure waves that compress the spinal cord from without, not from within, and propagate syrinx fluid caudally with each heartbeat, which leads to syrinx progression. ${ }^{23,24,50}$ Surgery limited to suboccipital craniectomy, C-1 laminectomy, and duraplasty eliminated this mechanism and relieved syringomyelia without the risk of more invasive procedures..$^{23,24,50}$ Since the mechanism responsible for syringomyelia associated with Chiari Type I malformation is occlusion of the subarachnoid space, in the current study we hypothesized that the same mechanism-occlusion of the subarachnoid space associated with increased amplitude of the subarachnoid CSF pulse pressure wave-is also the mechanism underlying syringomyelia in patients with PSS.

We postulate that the development and progression of PSS results from a mechanism of several steps that begins with obstruction of CSF flow within the SAS. This obstruction affects spinal CSF dynamics because the SAS accepts the fluid that is displaced from the intracranial subarachnoid cisterns as the brain expands during cardiac systole. In PSS, a subarachnoid block shortens the length of the SAS, reducing its compliance and impairing its ability to dampen the subarachnoid CSF pressure waves produced by brain expansion during cardiac systole. Spinal subarachnoid pressure waves that occur with every heartbeat would consequently have greater amplitude (pulse pressure) than normal and would act on the spinal cord above the block to drive CSF into the spinal cord, creating spinal cord edema that later coalesces into a syrinx. 23,26,50,56,63 After a syrinx is formed, the enlarged waves compress the external surface of the spinal cord, propel the syrinx fluid, and promote syrinx progression (Fig. 1) ${ }^{23,34,50}$ To test this hypothesis, we designed and carried out this prospective clinical investigation. Because surgery in patients with Chiari Type I malformation enhanced spinal CSF compliance, reduced subarachnoid CSF pressure and pulse pressure, and produced syrinx resolution and clinical stabilization or improvement, ${ }^{23,34,50}$

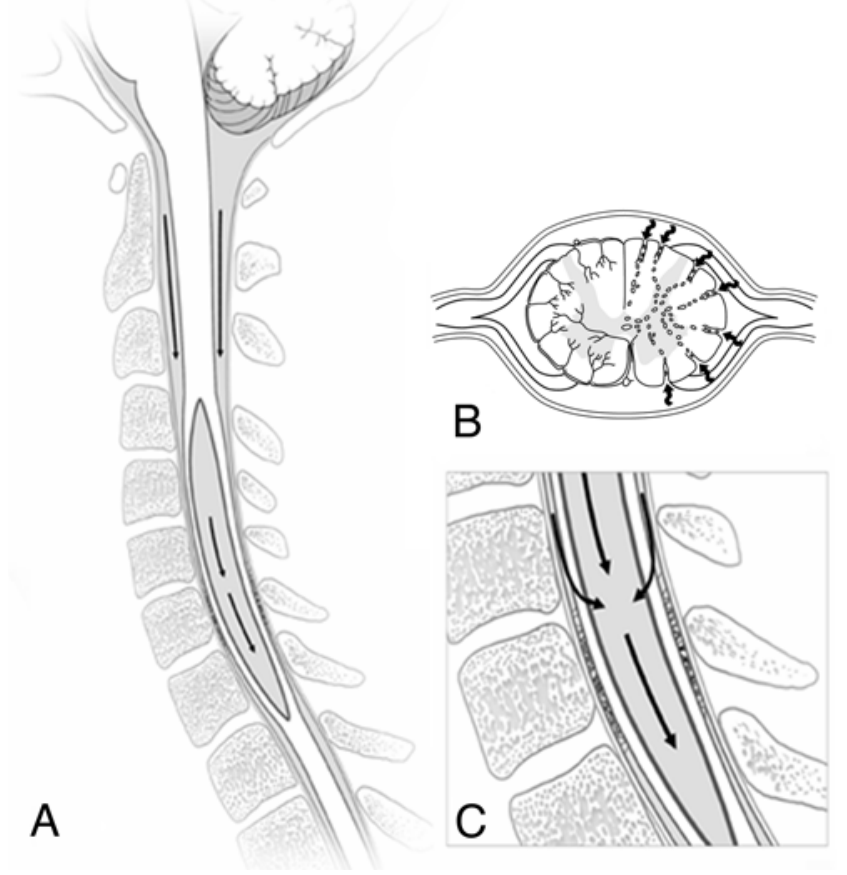

Fig. 1. Illustration of the proposed mechanism of syringomyelia formation and progression. A: Brain expansion during cardiac systole creates a CSF pressure wave (long, straight arrows), which is normally dissipated throughout the length of the spinal canal, particularly in the lumbar thecal sac. B: Obstruction of the SAS prevents normal damping of the CSF pressure wave, reduces compliance, and directs CSF into the Virchow-Robin spaces of the spinal cord by excess CSF pulsation (arrows). C: Over time, CSF within the central gray matter of the spinal cord coalesces into a syrinx. After formation of a syrinx, enlarged spinal CSF pressure waves (curved arrows) also act on the spinal cord to propel syrinx fluid and elongate the syrinx.

we anticipated that surgery for PSS that had similar effects on the spinal CSF physiology would engender a favorable clinical outcome. . $^{1,33,62}$

\section{Methods}

\section{Study Protocol}

Thirty-six adult patients (age range $26-58$ years, mean age $[ \pm \mathrm{SD}] 43.4 \pm 9.0)$ with PSS were enrolled in the clinical research protocol, "Establishing the Pathophysiology of Primary Spinal Syringomyelia (NINDS 01-N-0085)." Clinical trial registration no.: NCT00011245 (http://clinical trials.gov/ct2/show/NCT00011245?term=syringomyelia \&rank=2). We compared CSF pressure data obtained in these patients with those in 18 healthy adult participants (age range 23-61 years, mean $33.2 \pm 9.3$ years) previously obtained in the clinical protocol, "Establishing Normal CSF Physiology to Allow Comparison with Syringomyelic CSF Physiology (NINDS 94-N-0160)." 23 The institutional review board of the NINDS approved the research. Informed consent was obtained from each patient and each healthy volunteer. ${ }^{23}$ All patients and healthy volunteers were evaluated and treated at the Clinical Center of the National Institutes of Health.

All patients exhibited myelopathy caused by syrin- 
gomyelia. To enter the protocol all patients were required to have evidence of progressive neurological deterioration related to syringomyelia. Eighteen patients had a previous trauma, 14 reported no antecedent events, 2 had a history of meningitis, 1 had previously undergone Pantopaque (iophendylate) myelography, and 1 had a history of intramedullary tumor resection. Of the patients who had sustained a previous trauma, 13 patients had a history of spinal surgery associated with their trauma, 2 of whom had undergone an additional procedure to treat the syrinx. Of the 18 patients without a history of trauma, 9 patients had previously undergone procedures to treat their syringomyelia. Patients were evaluated before surgery, at 1 week and 3-6 months after surgery, and annually thereafter. The mean follow-up period after surgery was $4.8 \pm 3.4$ years (range 0.3-11.4 years).

\section{Preoperative Evaluation}

Clinical Evaluation. Grades for symptoms of sensory deficit, subjective weakness, dysesthetic pain, spasticity, impaired ambulation, and signs of muscle weakness were recorded. Gait and muscle weakness were graded using standard scales. The gait scale (each score in parentheses) was as follows: normal (0), unsteady or slow walking (1), walking with assistance (2), or nonambulatory (3). Muscle weakness was evaluated using the standard ASIA motor score scale: ${ }^{10}$ total paralysis (0), palpable or visible contraction (1), active movement, gravity eliminated (2), active movement against gravity (3), active movement against some resistance (4), and active movement against full resistance (5). The McCormick Scale was used to gauge the severity of myelopathy (Table 1): Grade I indicates that the patient is neurologically normal or has a mild focal deficit not significantly affecting function of involved limb; mild spasticity or reflex abnormality and a normal gait are present. Grade II indicates the presence of a sensorimotor deficit affecting the function of an involved limb; severe pain or dysesthetic syndrome impairing a patient's quality of life is present; the patient has mild to moderate difficulty with gate and still functions and ambulates independently. Grade III indicates a more severe neurological deficit; the patient has significant bilateral upper-extremity impairment, requires a cane/brace for ambulation, and may or may not function independently. Grade IV indicates a severe deficit; the patient requires a wheelchair or cane/brace and has bilateral upper-extremity impairment and is usually not independent. ${ }^{44}$

Radiological Imaging of Anatomy and Physiology. Cervical and thoracic T1-weighted MR images were obtained on a 1.5-T clinical scanner and evaluated by 2 independent examiners on a computer workstation (Carestream PACS, Carestream Health, Inc.). Low signal areas indicating regions of fluid were measured to determine and record the maximal anteroposterior diameter of the syrinx, the length of the syrinx, and the number of vertebral segments over which the syrinx extended.

Phase-contrast cine MR images of the cervical and thoracic spine were obtained in the sagittal plane for diagnostic purposes. In addition, phase-contrast cine MRI images were performed in the axial plane at C5-6 and in the thoracic spine in the region of the syrinx. Velocity and flow rates of CSF and syrinx fluid were obtained in the superior-inferior direction, with a positive sign denoting a velocity vector in the inferior direction and a negative sign indicating a vector in the superior direction (Signa Advantage Flow Analysis Software, Release 5.4, GE Medical Systems). Regions of interest included the subarachnoid space within the spinal canal and the syrinx.

Myelography was performed by injecting $10 \mathrm{ml}$ of iopamidol (Isovue-M 300, Bracco Diagnostics) through the lumbar needle at the conclusion of pressure recording (see Table 2). Placement of dye into the thecal sac was documented fluoroscopically, after which the head end of the myelography table was declined as much as $30^{\circ}$ in an attempt to advance the dye superiorly where it could outline lesions within the intradural space. The myelographic dye pattern was classified as 1) complete or nearcomplete block, 2) minor delay in dye flow, or 3) no apparent defect. Patients with a myelography-documented abnormality underwent spinal CT scanning that included the area of block or filling defect and 3 adjacent spinal levels superiorly and inferiorly. Patients in whom myelography showed normal findings underwent CT studies that included the region of the spinal cord affected by the syrinx and 3 adjacent spinal levels.

Spinal Subarachnoid Pressure Recording and Physiological Testing. The baseline mean and pulse pressures in the lumbar thecal and cervical subarachnoid spaces were measured, using fluoroscopic guidance, after insertion of 22-gauge spinal needles at the C1-2 and L4-5 levels. ${ }^{75}$ Cervical punctures were not performed in cases in which the dorsal CSF space at the C1-2 level was too small to safely perform the puncture or in which the patient declined the procedure. Simultaneous electrocardiography recording allowed analysis of pressure waves in relation to the phases of the cardiac cycle. Pressures were recorded at rest, during Valsalva maneuver, while coughing, and during jugular compression. For Valsalva testing, the individual blew into a tube for 12 seconds, with a target airway pressure of $40 \mathrm{~mm} \mathrm{Hg}$, and for cough pressure testing the individual was asked to cough normally 6 times. $^{72}$ To obtain pressure measurements during jugular compression, a blood pressure cuff was wrapped around the individual's neck loosely and rapidly inflated to $60 \mathrm{~mm} \mathrm{Hg}$ for 10 seconds at a time..$^{23,66}$ The cuff compressed the veins in the neck but did not close off the air passages or the blood flow to the head. ${ }^{30}$ The rate of rise of intrathecal pressure ( $\mathrm{mm} \mathrm{Hg} / \mathrm{second}$ ) during jugular compression was measured, as was the peak pressure. To measure compliance ( $\mathrm{ml} \mathrm{CSF} / \mathrm{mm} \mathrm{Hg}$ ), the change in pressure in the lumbar and cervical subarachnoid spaces in response to removal of $10 \mathrm{ml}$ of lumbar CSF was determined $(10 \mathrm{ml} /$ pressure change with CSF removal). Pressures were recorded on the hard disc drive of a Macintosh computer (Apple Computer, Inc.) using a system of Sorenson pressure transducers, a physiological monitor (Spacelabs Medical, Inc.), an analog-to-digital converter board (National Instruments Corp.), and data acquisition software (LabView, National Instruments 
J. D. Heiss et al.

TABLE 1: Clinical findings in 36 patients with PSS

\begin{tabular}{lccc}
\hline \multicolumn{1}{c}{ Symptom/Sign/Factor } & \multicolumn{3}{c}{ No. of Patients (\%) } \\
\cline { 2 - 3 } sensory deficit & Preop & 3 Mos Postop & Last Evaluation \\
subjective weakness & $36(100)$ & $33(92)$ & $33(92)$ \\
dysesthetic pain & $29(81)$ & $25(69)$ & $25(69)$ \\
spasticity & $24(67)$ & $21(58)$ & $22(61)$ \\
ambulation & $22(61)$ & $19(53)$ & $18(50)$ \\
normal (Grade 0) & & & $14(39)$ \\
slow and unsteady gait (Grade 1) & $13(36)$ & $18(50)$ & $5(14)$ \\
walking w/ aid (Grade 2) & $11(31)$ & $5(14)$ & $3(8)$ \\
nonambulatory (Grade 3) & $3(8)$ & $5(14)$ & $14(39)$ \\
ASIA score & $9(25)$ & $8(22)$ & $25(69)$ \\
$75-100$ & & & $6(17)$ \\
$50-74$ & $28(78)$ & $28(78)$ & $5(14)$ \\
$<50$ & $2(5)$ & $4(11)$ & $10(28)$ \\
McCormick grade & $6(17)$ & $4(11)$ & $7(19)$ \\
I & & & $5(14)$ \\
II & $7(19)$ & $10(28)$ & $14(39)$ \\
III & $11(31)$ & $10(28)$ & $28(78)$ \\
IV & $9(25)$ & $7(19)$ & $9(25)$ \\
good clinical outcome* & $9(25)$ & $33(92)$ &
\end{tabular}

* Good clinical outcome is defined as stable or improved McCormick grade.

Corp.). Recordings were displayed using graphical computer software (KaleidaGraph, Synergy Software). Pressure transducers were calibrated with a static water column. Cerebrospinal fluid samples were sent for routine laboratory analysis. ${ }^{23}$

\section{Evaluation During Surgery}

Surgical Procedure and Pressure Recording. The surgical procedure was performed after induction of general anesthesia. Before making the skin incision, a lumbar catheter was placed, and intrathecal pressure, at baseline and in response to jugular compression (Queckenstedt test) and sustained forced inspiration (using a mechanical ventilator to increase intrathoracic pressure to $40 \mathrm{~mm} \mathrm{Hg}$ for 12 seconds, as attempted with the Valsalva maneuver before and after surgery), was measured. In all cases the surgical approach was a laminectomy. The skin incision was centered over the region of the spine that contained the imaging-documented obstruction of the subarachnoid space. The Queckenstedt test was then repeated to assess for a block in CSF pressure transmission. Early in the study, syrinx pressure was measured after the dura and syrinx were punctured with a 22-gauge spinal needle under ultrasonographic guidance. ${ }^{54}$ Ultrasonic imaging (see next section) was used to identify places where the dura was separated by subarachnoid CSF from the spinal cord and could be opened more safely than in other areas where the dorsal CSF space was obliterated. The dura was opened above and below the region of obstruction while maintaining the underlying arachnoid mem- brane. A surgical plane was developed between the dura and the arachnoid membrane. The arachnoid membrane was then opened proximal and distal to the obstruction. Membranes representing scarred arachnoid at the level of obstruction often arose from the dorsal arachnoid or dorsal dura, crossed the subarachnoid space, and adhered to the spinal cord. The arachnoid was opened lateral to sites of previous durotomy and where the arachnoid or spinal cord adhered directly to the dorsal surface of the spinal cord. Lesions obstructing the subarachnoid space, including arachnoid cysts and arachnoid bands, were removed. Obstructed shunt tubes that remained from previous surgical approaches were removed only if they could be withdrawn with gentle traction; otherwise, they were cut flush to the surface of the spinal cord, and the extramedullary portion alone was removed. A duraplasty was performed using fascia lata allograft or pericardial xenograft in all cases. The wound was closed in layers.

Intraoperative Ultrasonography. Intraoperative ultrasonography was used to plan the approach to the intradural disease and to direct needle placement into the syrinx in cases in which it was performed. Ultrasonography identified the following: 1) intradural lesions, including adhesions within the SAS, 2) sites where the dorsal subarachnoid space was obliterated and the dorsal surface of the spinal cord appeared to be attached to the dura, and 3) normal anatomy at levels in which an unobstructed CSF space was present between the dura and spinal cord. The amplitude (mm) and timing of expansion and contraction (pulsation) of the spinal cord and syrinx during the cardiac cycle were observed. Changes in size of the syrinx 
during jugular compression and Valsalva maneuver were also noted.

\section{Postoperative Evaluation}

One week after surgery, CT myelography was repeated to evaluate the effect of the surgical procedure on CSF dye movement through the subarachnoid space across the site of surgery. Three months after surgery, patients returned to the National Institutes of Health for clinical assessment, MRI, and lumbar and cervical subarachnoid pressure testing. Grades for symptoms, gait, and muscle weakness were recorded as before surgery. The McCormick Scale grade measured 3 months after surgery was compared with the grade measured before surgery to determine functional outcome at this early time point (Table 1). ${ }^{44}$

Cervical and thoracic T1-weighted images were acquired using a 1.5-T clinical scanner, and studies were evaluated by the same method as preoperatively to determine and record the maximal anteroposterior diameter of the syrinx, the length of the syrinx, and the number of segments over which the syrinx extended.

The baseline mean and pulse pressures in the thecal and cervical SAS spaces were measured again at the C1-2 and L4-5 levels using the technique employed before surgery. ${ }^{75}$ Pressures were again recorded at rest, during Valsalva maneuver, during cough, and during jugular compression. Compliance measurements were performed as before surgery. ${ }^{23}$

Patients thereafter underwent clinical assessments and MRI annually. Grades for symptoms, gait, and muscle weakness were determined at each visit. The McCormick Scale grade measured at last follow-up was compared with the grade measured before surgery to determine long-term functional outcome. The result was deemed a "good clinical outcome" if at the patient's final visit the McCormick grade was the same or higher as the grade recorded before surgery, and the result was considered a "poor clinical outcome" if the McCormick grade was lower than before surgery. ${ }^{44}$

\section{Statistical Analysis}

Data are expressed as mean \pm SD. Values for CSF pressure obtained in patients before and after surgery were compared with those in healthy volunteers using the unpaired Student t-test. Test values determined in patients before surgery were compared with those after surgery using the paired Student t-test. Significance was set at $p$ $\leq 0.05$. Although each step of the proposed multiple-step process of syrinx formation and progression was tested in this protocol, the primary hypothesis was that the pulse pressure in the subarachnoid space above the level of the obstruction of the subarachnoid space (the cervical subarachnoid CSF pressure wave) in patients with syringomyelia was greater than normal.

In secondary analyses we evaluated for the presence or absence of other elements in the proposed mechanism of syrinx formation and progression: 1) anatomical obstruction of the SAS, as detected by spinal MRI and CT myelography; ${ }^{19,22,39}$ 2) reduced compliance of the cervical subarachnoid space; 3) transmission of spinal subarachnoid pulse pressure to the syrinx as seen on intraoperative ultrasonography; ${ }^{; 1,12,14,23,47,50,58,59}$ 4) physiological blockage of pressure transmission in the SAS; ${ }^{35-37}$ and 5) reduction in syrinx size after surgery, as measured by change in syrinx diameter and length on T1-weighted MRI. Secondary analyses also compared the clinical examination and physiological and anatomical factors after surgery with findings from before surgery. Finally, secondary analysis of the relationship of reduction in syrinx diameter after surgery to clinical outcome was performed after stratification of patients into "good clinical outcome" and "poor clinical outcome" groups.

\section{Results}

\section{Preoperative Evaluation}

Clinical Evaluation and Radiological Imaging. Before surgery, all patients had sensory deficits. Most patients had spasticity and symptoms of weakness and dysesthetic pain. One-quarter of patients were nonambulatory, many had gait instability, but just over one-third ambulated normally. The median preoperative McCormick grade was between II and III (range I-IV) (Table 1).

On MRI, the mean anteroposterior diameter of the syringes measured $7.1 \pm 2.8 \mathrm{~mm}$, and the mean length of the syringes measured $17.3 \pm 12.2 \mathrm{~cm}$. Syringes extended a mean of $9.1 \pm 5.2$ (range 1-19) spinal segments (Table 2, Fig. 2).

Phase-contrast cine MRI proved to be of little value diagnostically because motion of the heart and great vessels produced significant artifact in the thoracic spine where many of the syringes and subarachnoid space obstructions were located. In syringes that extended into the cervical spinal cord, phase-contrast cine MRI detected movement of the CSF and syrinx fluid in synchrony with the cardiac cycle (Fig. 3 ).

Myelography demonstrated the following: 1) complete or near-complete block in 11 patients, 2) minor delay in dye flow in 19, or 3) no apparent defect in 6. On CT myelography we observed a narrowing of the CSF column in the region of the segment of the spinal cord that contained the syrinx. In patients with myelographic blocks, the subarachnoid spaces around the spinal cord in the region of the syrinx were either devoid of contrast or reduced to a few narrow channels containing dye. Patients with minor or absent defects on myelography had CT myelography evidence of displacement of the spinal cord, including rotational distortion of the spinal cord in cases of arachnoiditis and flattening and anterior displacement of the spinal cord in cases in which there was an arachnoid cyst or diverticulum located dorsal to the spinal cord.

Spinal Subarachnoid Pressure Recording and Physiological Testing. Measurement of lumbar subarachnoid pressure was possible in all patients before surgery. Pressure measurement in the cervical subarachnoid space was not feasible in 4 patients, but was possible in all others. Cervical pulse pressure $(2.7 \pm 1.2 \mathrm{~mm} \mathrm{Hg})$, the primary outcome variable for the research study, was significantly elevated in patients compared with healthy volun- 
TABLE 2: Anatomy and CSF pressure recordings compared in 36 patients with syringomyelia and 18 healthy volunteers*

\begin{tabular}{|c|c|c|c|}
\hline \multirow[b]{2}{*}{ Parameter Measured } & \multicolumn{3}{|c|}{ Measurement ( $p$ value) } \\
\hline & Patients Before Surgery $\dagger$ & Patients After Surgery $\ddagger$ & Healthy Volunteers \\
\hline \multicolumn{4}{|l|}{ syrin $x$} \\
\hline diameter (mm) & $7.1 \pm 2.8$ & $3.6 \pm 3.8(0.0001) \S$ & NA \\
\hline length (cm) & $17.3 \pm 12.2$ & $11.2 \pm 12.4(0.0002) \S$ & NA \\
\hline length (no. of levels) & $9.1 \pm 5.2$ & $6.1 \pm 5.4(0.0001) \S$ & NA \\
\hline \multicolumn{4}{|l|}{ cervical pressure $(\mathrm{mm} \mathrm{Hg}) \dagger$} \\
\hline mean pressure & $12.1 \pm 2.6$ & $12.5 \pm 2.8(0.65)$ & $11.3 \pm 2.5(0.27)$ \\
\hline pulse pressure & $2.7 \pm 1.2 \S$ & $2.0 \pm 1.0(0.06)$ & $1.6 \pm 0.6(0.004)$ \\
\hline cervical compliance (ml CSF/mm Hg) & $3.2 \pm 1.9 \S$ & $4.1 \pm 2.8(0.54)$ & $6.0 \pm 4.0(0.002)$ \\
\hline \multicolumn{4}{|l|}{ lumbar pressure $(\mathrm{mm} \mathrm{Hg})$} \\
\hline mean & $12.1 \pm 3.0$ & $12.3 \pm 3.0(0.59)$ & $11.2 \pm 2.3(0.27)$ \\
\hline pulse & $0.7 \pm 0.5$ & $0.8 \pm 0.7(0.43)$ & $1.0 \pm 0.4(0.09)$ \\
\hline lumbar compliance (ml CSF/mm Hg) & $3.2 \pm 2.1 \S$ & $5.1 \pm 3.2(0.02) \S$ & $6.0 \pm 4.0(0.002)$ \\
\hline \multicolumn{4}{|l|}{ jugular compression } \\
\hline cervical upslope (mm Hg/sec) & $8.7 \pm 2.6 \rrbracket$ & $8.1 \pm 3.1(0.35)$ & $7.1 \pm 2.8(0.03)$ \\
\hline lumbar upslope (mm Hg/sec) & $4.4 \pm 3.7 \rrbracket$ & $5.2 \pm 3.1(0.11)$ & $6.1 \pm 2.0(0.03)$ \\
\hline peak cervical pressure $(\mathrm{mm} \mathrm{Hg})$ & $38.8 \pm 7.3$ & $38.3 \pm 6.2(0.59)$ & $35.3 \pm 9.0(0.18)$ \\
\hline peak lumbar pressure $(\mathrm{mm} \mathrm{Hg})$ & $30.0 \pm 13.1$ & $35.7 \pm 12.3(0.22)$ & $35.4 \pm 9.0(0.10)$ \\
\hline cervicolumbar differential $(\mathrm{mm} \mathrm{Hg})$ & $9.3 \pm 11.5 \pi$ & $3.0 \pm 11.0(0.09)$ & $-0.1 \pm 0.3(0.0001)$ \\
\hline \multicolumn{4}{|l|}{ Valsalva maneuver $(\mathrm{mm} \mathrm{Hg})$} \\
\hline cervical maximum value & $39.9 \pm 10.9$ & $38.0 \pm 10.8(0.11)$ & $41.8 \pm 6.7(0.52)$ \\
\hline lumbar maximum value & $38.2 \pm 9.5$ & $36.4 \pm 9.0(0.19)$ & $41.2 \pm 4.7(0.24)$ \\
\hline cervicolumbar differential & $1.4 \pm 4.3$ & $0.5 \pm 3.9(0.75)$ & $0.6 \pm 2.9(0.46)$ \\
\hline \multicolumn{4}{|l|}{ cough $(\mathrm{mm} \mathrm{Hg})$} \\
\hline cervical maximal & $27.3 \pm 17.5 \pi$ & $29.7 \pm 13.2(0.37)$ & $44.2 \pm 12.8(0.001)$ \\
\hline lumbar maximal & $37.3 \pm 20.6 \pi$ & $34.9 \pm 15.2(0.44)$ & $57.1 \pm 20.6(0.012)$ \\
\hline cervicolumbar differential & $-14.0 \pm 16.3$ & $-8.4 \pm 17.5(0.26)$ & $-13.0 \pm 11.3(0.81)$ \\
\hline $\begin{array}{l}\text { * Excluding parenthetical probability val } \\
\dagger \text { Four patients did not undergo cervica } \\
\text { † Six patients did not undergo physiolo } \\
\S \text { Significant difference compared with } \\
\text { ๆ Significant difference compared with }\end{array}$ & $\begin{array}{l}\text {, data are expressed as } \\
\text { incture before surgery. } \\
\text { a pressure testing after s } \\
\text { asurement before surger }\end{array}$ & $\begin{array}{l}\text { an } \pm \text { SD. Abbreviation: } \\
\text { (see Methods). } \\
\text { d t-test). }\end{array}$ & \\
\hline
\end{tabular}

teers $(1.6 \pm 0.6 \mathrm{~mm} \mathrm{Hg} ; \mathrm{p}=0.004)$ (Fig. 4). Mean cervical pressure did not differ significantly from normal. Lumbar mean and pulse pressures did not differ significantly between patients and healthy volunteers (Table 2).

Compliance in the cervical subarachnoid space was significantly decreased in patients compared with healthy volunteers (mean compliance $3.2 \pm 1.9 \mathrm{ml} \mathrm{CSF} / \mathrm{mm} \mathrm{Hg}$ in patients vs $6.0 \pm 4.0 \mathrm{ml} \mathrm{CSF} / \mathrm{mm} \mathrm{Hg}$ in healthy volunteers; $p=0.002)($ Table 2). Likewise, compliance in the lumbar subarachnoid space was significantly decreased in patients over healthy volunteers $(3.2 \pm 2.1$ vs $6.0 \pm 4.0$ $\mathrm{ml} \mathrm{CSF} / \mathrm{mm} \mathrm{Hg}$, respectively; $\mathrm{p}=0.002$ ).

The rate of CSF pressure transmission to the thecal sac (Queckenstedt test) was compromised in patients with PSS $(4.4 \pm 3.7 \mathrm{~mm} \mathrm{Hg} / \mathrm{sec})$ compared with healthy volunteers $(6.1 \pm 2.0 \mathrm{~mm} \mathrm{Hg} / \mathrm{sec})(\mathrm{p}=0.03)$ (Table 2, Fig. 5 ). The Valsalva maneuver increased cervical and lumbar pressure to a similar extent. The pressure differential be- tween the cervical and lumbar subarachnoid space during Valsalva maneuver was only $1.4 \mathrm{~mm} \mathrm{Hg}$. A cough resulted in increases in cervical and lumbar pressure of 15.2 and $25.2 \mathrm{~mm} \mathrm{Hg}$ from the baseline pressure in patients, respectively, compared with 32.9 and $45.9 \mathrm{~mm} \mathrm{Hg}$ from baseline pressure, respectively, in healthy participants ( $p$ $=0.001$ and 0.012 , respectively). Cervicolumbar pressure differential while coughing was $-14.0 \mathrm{~mm} \mathrm{Hg}$ in patients and $-13.0 \mathrm{~mm} \mathrm{Hg}$ in healthy volunteers (Table 2).

\section{Intraoperative Evaluation}

Intraoperative ultrasonography demonstrated that the spinal cord was expanded by the syrinx and the subarachnoid space was obliterated in cases of severe arachnoiditis. Axial ultrasonographic images revealed, in some cases, extension of the syrinx into the anterior horns of the spinal cord. When arachnoiditis was less severe, septa could be seen traversing the subarachnoid space that 

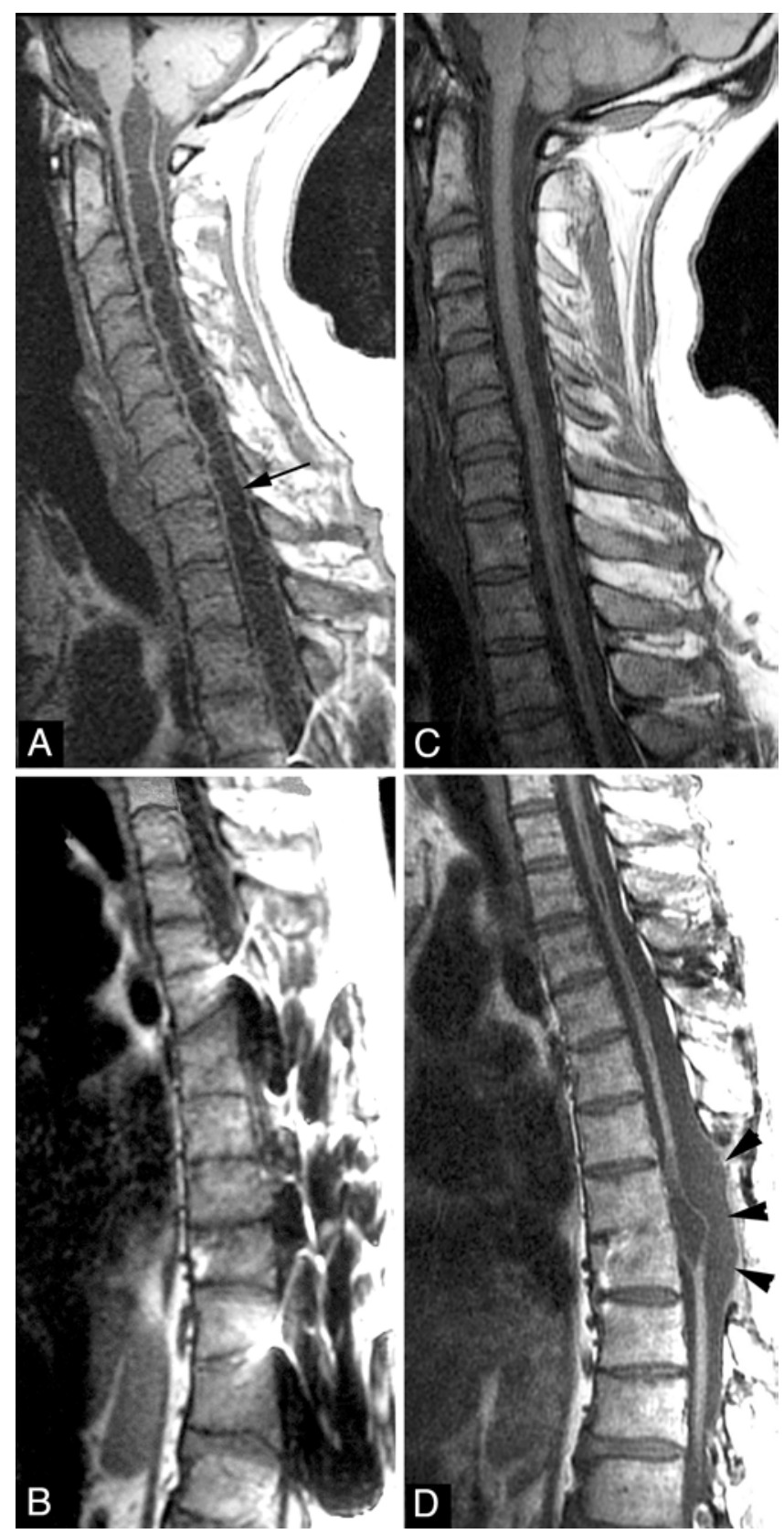

FIG. 2. Midsagittal T1-weighted MRI studies of the cervical and thoracic spine in a 35-year-old paraplegic man with previous fracturedislocation at the T8-9 level. The patient developed posttraumatic syringomyelia (A, arrow) above the level of his injury (B), which is obscured by metal artifact. One year after T-8 and T-9 laminectomies, intradural exploration with reestablishment of the subarachnoid space, duraplasty, and removal of instrumentation, MRI demonstrated resolution of the cervicothoracic syrinx (C), myelomalacia at the level of the previous spinal cord injury, and enlargement of the subarachnoid space (D, arrowheads).

would sometimes bow medially or laterally during systole. Pulsation of the syrinx occurred in synchrony with the cardiac cycle in all patients (Fig. 6). Syrinx pulsations were less prominent in patients that had reduced CSF pulse pressure during surgery, presumably from inadvertent loss of CSF during placement of the lumbar drain.

\section{Evaluation After Surgery}

Clinical Evaluation and Radiological Imaging. After surgery, most patients reported stable or improved dysesthetic pain and spasticity and had stable or improved muscle strength, as determined by ASIA grades. Three months after surgery (short-term outcome) there were 33 patients with good outcomes, with 4 patients improving a single McCormick grade and 29 patients remaining at the same grade as before surgery. Three patients declined a single McCormick grade and were deemed to have poor short-term outcomes. At final evaluation, 28 patients achieved a good outcome (Table 1). The mean follow-up periods were 5.3 years for patients with a good outcome and 4.2 years for those with a poor outcome.

On 3-month MRI, the mean syrinx diameter (3.6 \pm $3.8 \mathrm{~mm} ; \mathrm{p}<0.0001)$, length $(11.2 \pm 12.4 \mathrm{~cm} ; \mathrm{p}=0.0002)$, and span (the number of levels over which the syrinx extended $6.1 \pm 5.4$ segments; $\mathrm{p}<0.0001$ ) were significantly less than they were before surgery (Table 2; Fig. 7).

Myelography was repeated 1 week after surgery and demonstrated the following: 1) a complete or near-complete block associated with arachnoiditis in the region of surgery in 6 patients, 2) minor delay in dye flow in 9 , and 3) no apparent defect in 19. Two patients declined myelography. Three of 6 patients with complete or nearcomplete subarachnoid space obstruction not relieved by surgery had a poor outcome on 3-month evaluation, and the remaining patients had a poor outcome on 1-year evaluation. In patients in whom myelographic blocks were absent, CT myelography demonstrated expansion of the dorsal subarachnoid space under the duraplasty (Fig. 2D).

Spinal Subarachnoid Pressure Recording and Physiological Testing. Lumbar subarachnoid pressure measurements were performed in 30 patients and in the cervical SAS in 22 patients after surgery. Lumbar compliance after surgery $(5.1 \pm 3.2 \mathrm{ml} \mathrm{CSF} / \mathrm{mm} \mathrm{Hg})$ increased (before surgery $3.2 \pm 2.1 \mathrm{ml} \mathrm{CSF} / \mathrm{mm} \mathrm{Hg} ; \mathrm{p}=$ 0.02). Cervical compliance, cervical and lumbar mean and pulse pressure, and lumbar pressure during jugular compression did not change significantly in these patients (Table 2).

Secondary Analysis of Treatment Outcome by Syrinx Size, Extent of Disease, and Physiological Factors. The 28 patients with a good long-term clinical outcome had significant reduction in the diameter $(p<0.0001)$ and length $(p=0.0002)$ of their syringes (Table 3$)$. On the other hand, the mean width and length of the syrinx did not decrease following surgery in the 8 patients with poor clinical outcome (Table 3). A good clinical outcome after surgery was also associated with smaller $(\mathrm{p}=0.0003$, chi-square test) and shorter $(\mathrm{p}=0.004$, chi-square test) syringes before surgery. Twenty-four of 26 patients with intradural scarring that was localized and could be relieved by a laminectomy of 4 or fewer levels had good outcomes; in contrast, only 4 of 10 patients with more extensive laminectomy had a good outcome $(p=0.0009$, chi-square test). A postoperative reduction in syrinx size was inversely related to the number of spinal levels that were explored in an attempt to open the SAS (Fig. 7). 

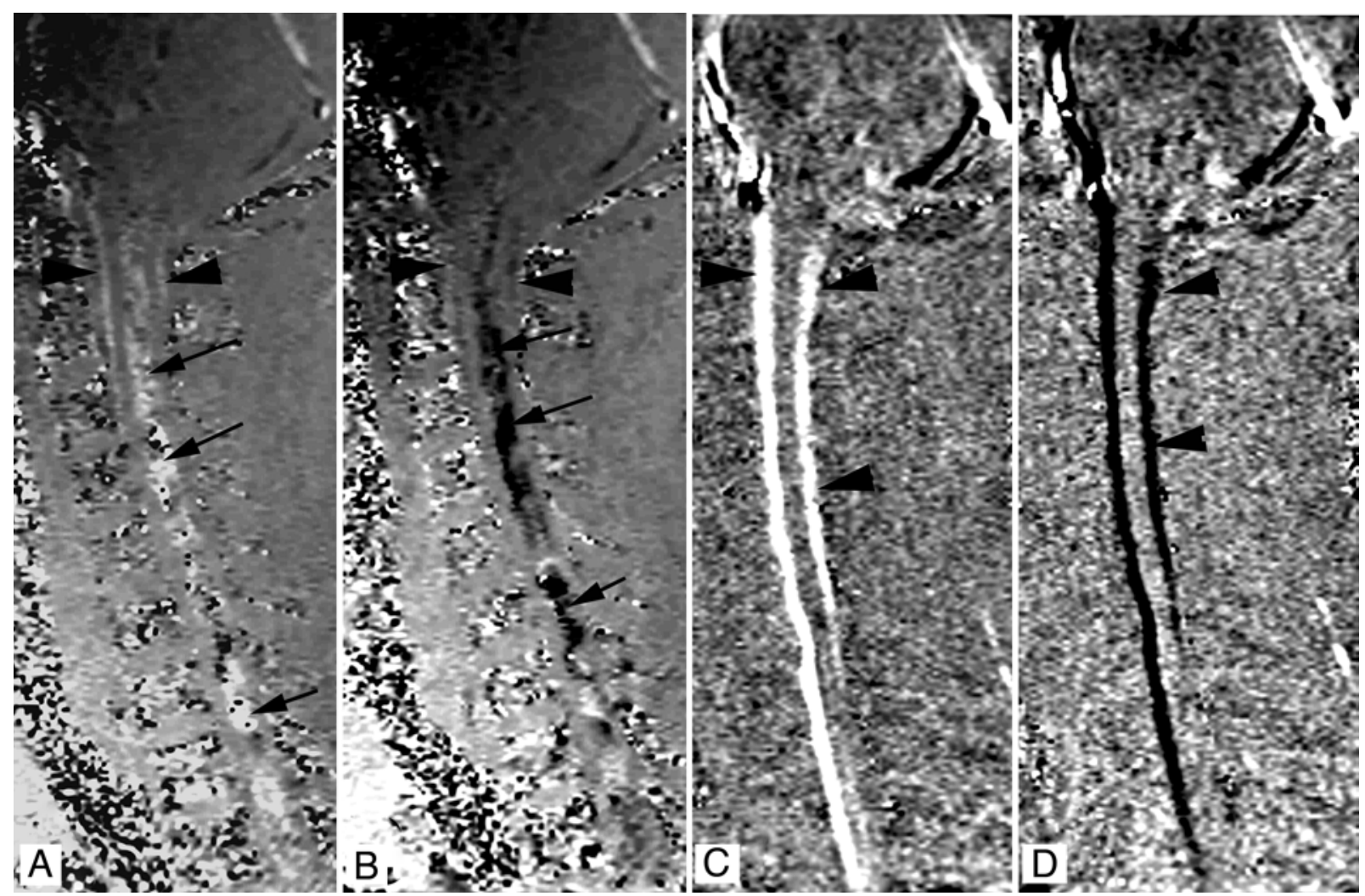

FIG. 3. Sagittal phase-contrast cine MRI scans of the cervical spine before (A and B) and 1 year after surgery (C and D) obtained in the patient described in Fig. 2. Pulsatile flow is present in the syrinx before surgery. Fluid flow in the inferior direction (during systole) is white, and in the superior direction (during diastole) is black. Before surgery inferior flow is present within the upper cervical subarachnoid space (arrowhead) and the syrinx (arrows) during systole (A) and superior flow is present in the same locations during diastole (B). After surgery, the syrinx has resolved, and fluid flow during systole (C) and diastole (D) is confined to the SAS (arrowheads).

Physiological pressure recordings were performed in 23 of the 28 patients with a good outcome and in 7 of the 8 patients with a poor outcome. In the patients with good outcome, cervical pulse pressure, which was elevated before surgery $(2.5 \pm 0.9 \mathrm{~mm} \mathrm{Hg}$ in patients vs $1.6 \pm 0.6 \mathrm{~mm}$ $\mathrm{Hg}$ in healthy volunteers; $\mathrm{p}=0.002)$, trended lower after surgery (patients $2.1 \pm 0.9 \mathrm{~mm} \mathrm{Hg} ; \mathrm{p}=0.28$ ). Cervical compliance, which was significantly less than normal before surgery, increased toward normal after surgery in the patients with good outcome but was reduced further in patients with poor outcome (Table 3). The pressure transmission across the subarachnoid block in good-outcome patients improved significantly after surgery, as indicated by a reduction in the cervicolumbar pressure differential $(\mathrm{p}=0.02)$ (Table 3$)$. In patients with poor outcome the pressure transmission across the subarachnoid block was further impaired after surgery, as shown by an increase in the cervicolumbar pressure differential $(\mathrm{p}=0.01)$ (Table 3). Patients in the poor outcome group also had significant elevations in cervical pulse pressure before surgery (3.0 $\pm 2.0 \mathrm{~mm} \mathrm{Hg}$ in patients vs $1.6 \pm 0.6 \mathrm{~mm} \mathrm{Hg}$ in healthy volunteers; $\mathrm{p}=0.01$ ).

\section{Discussion}

The mechanism of PSS was evaluated by clinical, radiographic, and physiological tests performed before, during, and after surgery. Magnetic resonance imaging, CT myelography, and intraoperative ultrasonography identified obstruction of the subarachnoid space in all patients. The Queckenstedt test detected a physiological block to pressure transmission across the region of subarachnoid block in the patient group as a whole. In patients with apparently normal-pressure transmission within the spine, intraoperative ultrasonography provided evidence of partial obstruction and septa in the SAS and real-time demonstration of spinal CSF pulsations directed toward the spinal cord and syrinx. In these patients, the measured compliance within the cervical subarachnoid space was reduced, and the cervical pulse pressure was elevated. Surgery that effectively opened the SAS resulted in reduction in syrinx diameter and stabilization or improvement in myelopathy. ${ }^{17,27,53}$ On the other hand, when surgery was ineffective, which mainly occurred in patients with obstruction of the subarachnoid space over a length of more than 4 vertebral segments, it failed to open the SAS and did not result in reduction in syrinx diameter or stabilization of myelopathy (Table 3). All of these findings are consistent with a mechanism of syringomyelia that is extramedullary, not intramedullary.

Surgery produced a reduction in syrinx size that was inversely related to the number of spinal segments 


\section{Syringomyelia pathophysiology}

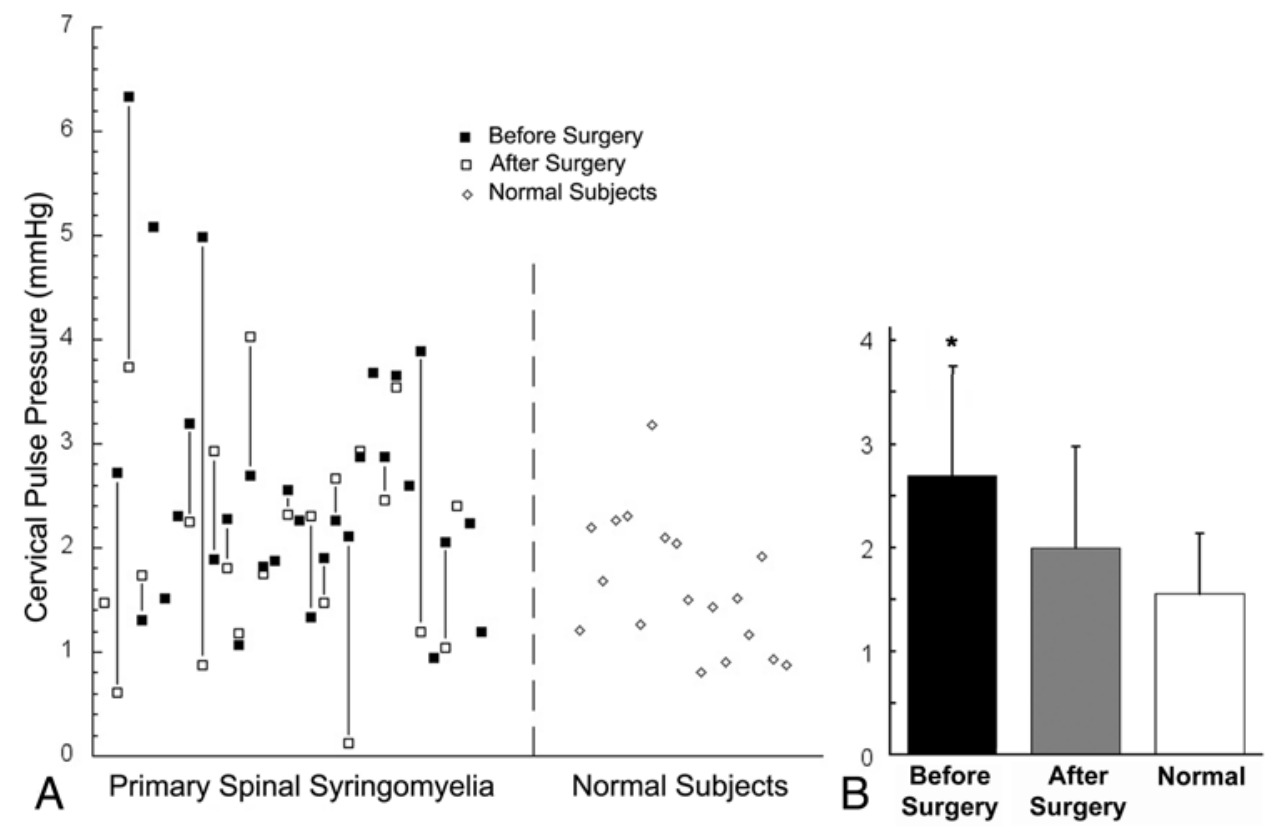

FIG. 4. Graphs demonstrating the pulse pressure in the cervical subarachnoid space in patients with PSS (before and after surgery) and in healthy volunteers (normal subjects) (A). Before surgery the cervical pulse pressure was significantly $\left({ }^{*} p<0.004\right)$ increased in the PSS group compared with healthy controls (B).

that needed to be explored in an attempt to open the obstructed SAS (Fig. 7). When the obstruction of the CSF passages around the spinal cord was short in length (1-3 spinal segments) and located in one region of the spine, surgical removal of the obstruction reversed the physiological abnormalities and provided long-term resolution of syringomyelia. ${ }^{13,33,62}$ However, in cases in which CT myelography and surgical observations indicated that scarring was widespread within the spinal subarachnoid pathways, surgery usually was unable to open the CSF pathways even when the laminectomy was extended over 4-10 spinal segments. Limited success in relieving syringomyelia associated with extensive arachnoiditis suggests that alternative approaches, such as the shunting of CSF or syrinx fluid to a site that can accept and absorb the fluid, should be considered in such cases.

The radiographic tests that were used in this protocol proved to be complementary. Conventional MRI identified the presence, diameter, and length of the syrinx and, in some cases, indicated the location of arachnoiditis or an arachnoid cyst within the subarachnoid space. Myelography identified the inferior and superior margin of a block, and CT myelography provided additional anatomical detail, including displacement of the spinal cord by intradural arachnoiditis or arachnoid cysts. In many cases, obstruction of the subarachnoid space was not complete in the region of focal arachnoiditis, permitting dye passage and pressure transmission. ${ }^{43}$ Intraoperative ultrasonography was the most sensitive imaging modality for displaying abnormal local anatomy of the SAS and spinal cord. A syrinx that appeared to be a single cavity on MRI often appeared to be 2 or 3 parallel syrinx cavities on ultrasonographic images. Arachnoid bands, which were invisible or appeared as single bands on MRI, appeared on intraoperative ultrasonography as numerous bands bridging from the dorsal dura or arachnoid to the spinal cord. Ultrasonography was the only modality that detected the pulsation of the walls of the syrinx.

A Queckenstedt test, Valsalva maneuver, and cough test have been hypothesized to create pressure differentials between the subarachnoid spaces superior and inferior to obstruction of the SAS. A physiological block in CSF pressure transmission was detected using the Queckenstedt test in the present study. Sgouros and Williams $^{62}$ have hypothesized that a pressure differential is created between the cervical and lumbar subarachnoid
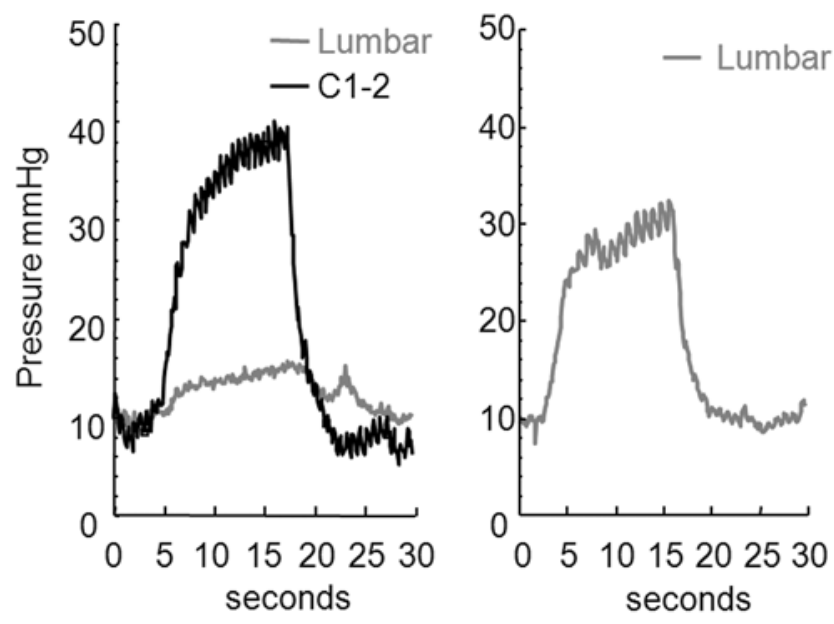

Fıg. 5. Graphs demonstrating the changes in lumbar subarachnoid space pressure in response to jugular compression before (left) and after (right) surgery in the patient featured in Figs. 2 and 3. Before surgery the rise in lumbar pressure is slower and much less than the cervical pressure. After surgery, lumbar pressure rises more rapidly and to a higher level than before surgery. (Cervical pressure recording was not performed after surgery at the patient's request.) 

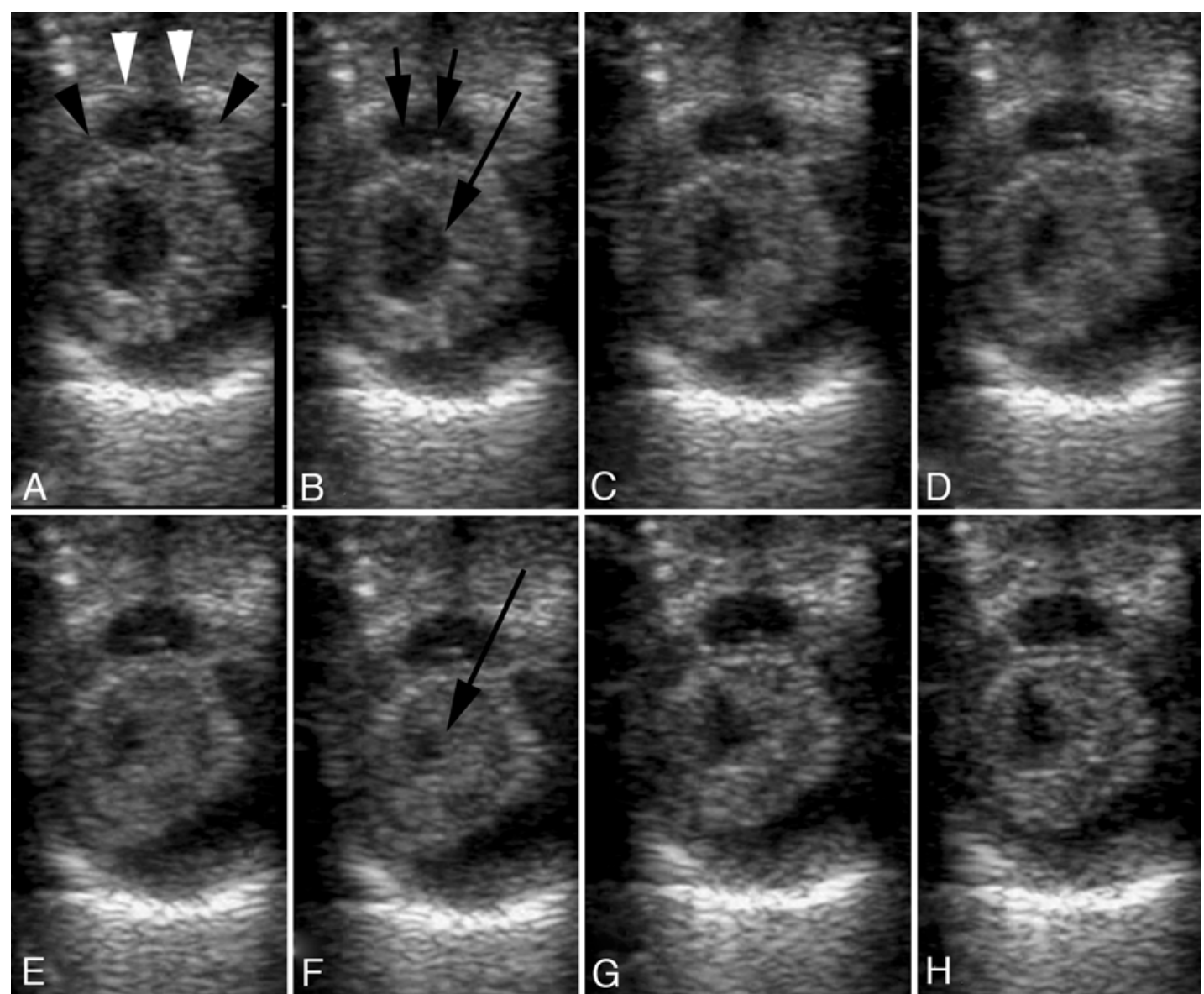

FIG. 6. Intraoperative axial cardiac-gated ultrasonographic images obtained after thoracic laminectomy in a patient with PSS. Frames in late diastole (A and $B$ ) are followed by frames in systole $(C-F)$ and early diastole $(G$ and $H)$. Fibrous tissue bands are seen (A, black arrowheads) that traverse the subarachnoid space and pass from the spinal cord surface to the dura (white arrowheads). These bands isolate the dorsal subarachnoid space (B, short black arrows) from the remainder of the subarachnoid space. The syrinx ( $\mathrm{B}$, long arrow) is located slightly to the right of the center of the spinal cord and is at its maximal diameter during cardiac diastole. During cardiac systole, the syrinx diameter becomes smaller (F, long arrow) as the anterior and lateral surface of the spinal cord flatten in response to the adjacent CSF pulse wave.

spaces during Valsalva maneuver and cough test and that this pressure differential has a role in syrinx progression. We observed no significant pressure differentials during Valsalva maneuver. During a cough, the pressure in the lumbar and cervical subarachnoid spaces rose rapidly; the maximal lumbar pressure exceeded that in the cervical subarachnoid space, which created brief periods during which pressure differentials existed in the SAS. However, cervicolumbar subarachnoid pressure differentials were similar to those measured in healthy volunteers, which suggests that they do not have a role in syrinx pathogenesis (Table 2).

Standard care of PSS consists of surgical approaches that do the following: 1) open obstructed CSF pathways or 2) shunt CSF or syrinx fluid. The most common procedure for PSS is laminectomy. Lesions obstructing the subarachnoid space, such as tumors and arachnoid cysts, are removed through the laminectomy opening. Many surgeons combine the laminectomy procedure with a duraplasty in which a tissue graft is used to expand the dura. In other instances, compression of the subarachnoid space is anterior to the spinal cord. Anterior lesions are

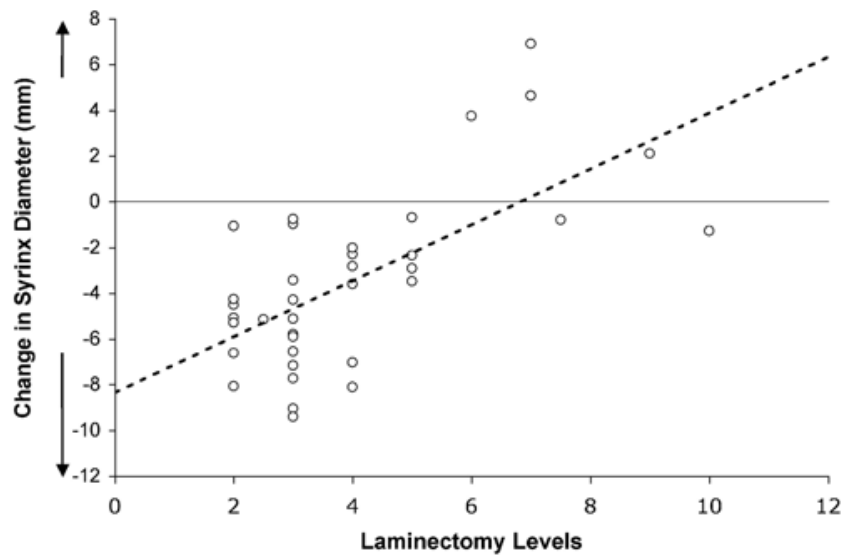

FIG. 7. Graph showing the change in syrinx diameter $(\Delta S)$ that resulted from surgical treatment in relation to the number of spinal levels $(\mathrm{L})$ that were explored in an attempt to open the SAS. In patients with more extensive disease, there was less reduction in syrinx diameter $(\mathrm{mm})$ after surgery. The dotted line indicates a linear regression $\left(\mathrm{R}^{2}\right.$ $=0.42 ; p<0.0001$ ) of this relationship, as expressed in the following formula: $\Delta S=1.2 \mathrm{~L}-8.4 \mathrm{~mm}$. 
Syringomyelia pathophysiology

TABLE 3: Anatomy and CSF pressure recordings stratified by outcome*

\begin{tabular}{|c|c|c|c|c|}
\hline \multirow[b]{2}{*}{ Measurement } & \multicolumn{2}{|c|}{ Good-Outcome Patients $(n=28)$} & \multicolumn{2}{|c|}{ Poor-Outcome Patients $(n=8)$} \\
\hline & Before Surgery & $\begin{array}{l}\text { After Surgery } \dagger \\
\quad(p \text { value })\end{array}$ & Before Surgery & $\begin{array}{l}\text { After Surgery } \dagger \\
\quad(p \text { value })\end{array}$ \\
\hline \multicolumn{5}{|l|}{ syrinx } \\
\hline diameter (mm) & $7.3 \pm 3.0$ & $2.9 \pm 3.9(0.001) \S$ & $6.3 \pm 2.2$ & $6.0 \pm 2.6(0.81)$ \\
\hline length (cm) & $15.2 \pm 11.4$ & $8.1 \pm 9.8(0.0002) \S$ & $24.5 \pm 13.0$ & $22.2 \pm 14.7(0.41)$ \\
\hline length (levels) & $8.5 \pm 4.9$ & $4.7 \pm 4.4(0.0001) \S$ & $11.3 \pm 5.9$ & $10.9 \pm 6.0(0.69)$ \\
\hline \multicolumn{5}{|l|}{ cervical pressure $(\mathrm{mm} \mathrm{Hg}) \ddagger$} \\
\hline mean pressure & $12.2 \pm 2.4$ & $12.6 \pm 3.0(0.72)$ & $11.9 \pm 3.6$ & $12.2 \pm 2.5(0.82)$ \\
\hline pulse pressure & $2.5 \pm 0.9$ & $2.1 \pm 0.9(0.28)$ & $3.0 \pm 2.0$ & $1.7 \pm 1.7(0.007) \S$ \\
\hline cervical compliance (ml CSF/mm Hg) & $3.2 \pm 1.9$ & $4.3 \pm 3.0(0.49)$ & $3.4 \pm 2.0$ & $2.9 \pm 0.5(0.81)$ \\
\hline \multicolumn{5}{|l|}{ lumbar pressure $(\mathrm{mm} \mathrm{Hg})$} \\
\hline mean & $12.2 \pm 2.5$ & $12.5 \pm 3.1(0.30)$ & $11.9 \pm 4.5$ & $11.5 \pm 2.3(0.94)$ \\
\hline pulse & $0.8 \pm 0.6$ & $0.8 \pm 0.5(0.97)$ & $0.4 \pm 0.2$ & $0.9 \pm 1.0(0.23)$ \\
\hline lumbar compliance $(\mathrm{ml} / \mathrm{mm} \mathrm{Hg})$ & $3.5 \pm 1.9$ & $4.8 \pm 2.3(0.06)$ & $2.6 \pm 3.0$ & $5.3 \pm 5.9(0.30)$ \\
\hline \multicolumn{5}{|l|}{ jugular compression } \\
\hline cervical upslope (mm Hg/sec) & $8.6 \pm 2.5$ & $7.7 \pm 2.3(0.27)$ & $9.7 \pm 3.0$ & $10.2 \pm 4.5(0.59)$ \\
\hline lumbar upslope (mm Hg/sec) & $4.5 \pm 3.8$ & $5.9 \pm 3.1(0.07)$ & $3.2 \pm 2.0$ & $2.8 \pm 1.0(0.48)$ \\
\hline peak cervical pressure $(\mathrm{mm} \mathrm{Hg})$ & $38.5 \pm 6.6$ & $37.9 \pm 4.2(0.67)$ & $40.9 \pm 10.0$ & $40.0 \pm 11.1(0.47)$ \\
\hline peak lumbar pressure (mm Hg) & $32.4 \pm 11.5$ & $36.7 \pm 7.8(0.07)$ & $21.4 \pm 14.1$ & $17.2 \pm 13.4(0.02) \S$ \\
\hline cervicolumbar differential (mm Hg) & $6.4 \pm 8.3$ & $1.3 \pm 3.5(0.02) \S$ & $12.5 \pm 15.8$ & $17.7 \pm 15.0(0.01) \S$ \\
\hline \multicolumn{5}{|l|}{ Valsalva maneuver $(\mathrm{mm} \mathrm{Hg})$} \\
\hline cervical maximum value & $42.9 \pm 8.7$ & $40.7 \pm 8.9(0.22)$ & $38.2 \pm 16.4$ & $31.3 \pm 14.8(0.14)$ \\
\hline lumbar maximum value & $40.7 \pm 8.3$ & $39.3 \pm 7.3(0.32)$ & $34.0 \pm 12.5$ & $30.1 \pm 10.7(0.23)$ \\
\hline cervicolumbar differential & $0.6 \pm 3.1$ & $0.7 \pm 3.9(0.94)$ & $4.1 \pm 6.1$ & $0.2 \pm 4.5(0.30)$ \\
\hline \multicolumn{5}{|l|}{ cough (mm Hg) } \\
\hline cervical maximal & $27.6 \pm 14.8$ & $32.5 \pm 13.2(0.19)$ & $18.6 \pm 6.8$ & $12.7 \pm 5.5(0.49)$ \\
\hline lumbar maximal & $38.4 \pm 24.6$ & $34.7 \pm 16.2(0.32)$ & $32.2 \pm 21.3$ & $36.0 \pm 17.2(0.45)$ \\
\hline cervicolumbar differential & $-14.4 \pm 12.1$ & $-5.4 \pm 8.1(0.12)$ & $-11.6 \pm 12.8$ & $-26.6 \pm 20.8(0.57)$ \\
\hline
\end{tabular}

inaccessible via the laminectomy approach, and relief of the obstruction requires an anterior or anterolateral approach to correct a spinal deformity that compresses the spinal subarachnoid CSF pathways.

In addition to surgical approaches that relieve the obstruction in the SAS, PSS is also treated using shunts to divert syrinx or cerebrospinal fluid. The most common syrinx shunts are syringosubarachnoid, syringoperitoneal, and syringopleural shunts. Although these therapeutic options are often initially successful, they are associated with a higher rate of morbidity, shorter duration of effectiveness, and greater incidence of syringomyelia recurrence than procedures that reconstruct the SAS. ${ }^{62}$ Placing a shunt tube in the spinal cord has a reported risk of creating a new neurological deficit of $20 \% .^{2}$ Delayed spinal cord injury due to blockage or infection of a syrinx shunt can also occur. ${ }^{5,61,70}$ In the largest series of patients with posttraumatic syringomyelia, both reconstruction of the SAS $(n=18)$ and syrinx shunting $(n=34)$ resulted in an
$88 \%$ success rate at 6 months after surgery. However, at 6 years postoperatively the success rate for reconstruction of the SAS was $80 \%$, compared with $50 \%$ for shunting. ${ }^{62}$ Occlusion of the shunts leads to delayed malfunction. Our study confirms the favorable outcome of using an approach designed to address the basis of posttraumatic syringomyelia, an obstruction to the free, pulsatile movement of CSF in the SAS, via laminectomy and duraplasty, particularly when the lesion in the SAS after spinal trauma is localized and can be removed and bridged surgically.

Primary spinal syringomyelia also may be associated with diffuse, rather than focal, obstruction of the SAS. The inflammatory response to infectious or chemical meningitis creates arachnoiditis that obliterates the subarachnoid space by creating extensive fibrous scarring in the SAS. In such cases, radiographic evaluation often demonstrates that subarachnoid space obstruction extends over so many spinal levels that decompression 
and duraplasty cannot practically relieve it, and shunting of syrinx fluid or CSF are alternative treatments. When the proximal end of the shunt is placed in the syrinx, the distal end of the shunt must be placed where drainage is unobstructed, either in the subarachnoid space superior to the block or in the pleural or peritoneal cavity. The disadvantages of shunting the syrinx directly include immediate and delayed spinal cord injury and the inability to drain more than one chamber of a multiloculated syrinx. Some investigators have advocated shunting of the CSF rather than the syrinx fluid because syrinx fluid appears to arise from spinal subarachnoid $\mathrm{CSF}^{45,48}$ In PSS, shunting of CSF from the SAS has been performed with catheters placed superior to the block of the SAS. ${ }^{64,67,68}$ Shunting of CSF to the peritoneal cavity would remove the fluid, increase compliance, and lower the subarachnoid pulse pressure that drives CSF into the syrinx. In summary, when syringomyelia is associated with arachnoiditis that extends over more than 4 spinal levels, shunting of syrinx fluid or CSF appears to be a reasonable approach.

\section{Conclusions}

The goal of this study was to establish the mechanism of progression of PSS. ${ }^{4}$ We hypothesized that PSS results from obstruction of CSF flow in the SAS; this obstruction affects spinal CSF dynamics because the SAS accepts the CSF that is rapidly displaced from the intracranial subarachnoid space as the brain expands during cardiac systole. In PSS, a subarachnoid block effectively shortens the length of the SAS, reducing CSF compliance and the capacity of the spinal theca to dampen the subarachnoid CSF pressure waves produced by brain expansion during cardiac systole. As a result, exaggerated spinal subarachnoid pressure waves occur with every heartbeat and act on the spinal cord above the block to drive CSF into the spinal cord and create a syrinx..$^{23,26,34,50,56,63}$ After a syrinx is formed, the enlarged subarachnoid pressure waves compress the external surface of the spinal cord, propel the syrinx fluid, and promote syrinx progression (Fig. 1). ${ }^{23,34,50}$ A surgical procedure that successfully opens the SAS can correct the underlying pathophysiology of PSS and eliminate the syrinx. Invasion of the spinal cord with shunts is unnecessary in such cases.

Finally, the pathophysiological mechanism identified in the current study is identical to the mechanism that our prior studies have demonstrated for syringomyelia associated with subarachnoid space obstruction at the level of the foramen magnum in patients with Chiari Type I malformation and patients with persistent syringomyelia after prior surgery for Chiari Type I malformation. ${ }^{23,24,50}$ Thus, a single mechanism, rather than multiple separate mechanisms, seems to underlie syringomyelia associated with obstruction of the SAS, whether it is a lesion at the foramen magnum or at a lower level.

\section{Disclosure}

This research was supported by the Intramural Research Program of the NINDS at the NIH.

Author contributions to the study and manuscript preparation include the following. Conception and design: Heiss, Eskioglu, Oldfield. Acquisition of data: Heiss, Snyder, Peterson, Patronas, Butman, Smith, DeVroom, Sansur, Eskioglu, Kammerer. Analysis and interpretation of data: Heiss, Snyder, Peterson, Sansur, Eskioglu, Oldfield. Drafting the article: Heiss, Oldfield. Critically revising the article: all authors. Reviewed submitted version of manuscript: all authors. Approved the final version of the manuscript on behalf of all authors: Heiss. Statistical analysis: Heiss, Snyder, Peterson. Administrative/technical/material support: Patronas, Butman, Smith, DeVroom, Sansur, Eskioglu, Kammerer, Oldfield. Study supervision: Oldfield.

\section{Acknowledgments}

The authors thank Dr. Kathryn A. Jarvis and Ms. Hanh Nguyen for their assistance in the pressure testing procedures.

\section{References}

1. Andrews BT, Weinstein PR, Rosenblum ML, Barbaro NM: Intradural arachnoid cysts of the spinal canal associated with intramedullary cysts. J Neurosurg 68:544-549, 1988

2. Barbaro NM: Surgery for primarily spinal syringomyelia, in Batzdorf U (ed): Syringomyelia: Current Concepts in Diagnosis and Treatment. Baltimore: Williams \& Wilkins, 1991, pp 183-198

3. Batzdorf U: Primary spinal syringomyelia. J Neurosurg Spine 3:429-435, 2005

4. Batzdorf U (ed): Classification of syringomyelia, in: Syringomyelia: Current Concepts in Diagnosis and Treatment. Baltimore: Williams \& Wilkins, 1991, pp 1-2

5. Batzdorf U, Klekamp J, Johnson JP: A critical appraisal of syrinx cavity shunting procedures. J Neurosurg 89:382-388, 1998

6. Caplan LR, Norohna AB, Amico LL: Syringomyelia and arachnoiditis. J Neurol Neurosurg Psychiatry 53:106-113, 1990

7. Castillo M, Quencer RM, Green BA, Montalvo BM: Syringomyelia as a consequence of compressive extramedullary lesions: postoperative clinical and radiological manifestations. AJR Am J Roentgenol 150:391-396, 1988

8. Clifton AG, Ginsberg L, Webb WJ, Valentine AR: Idiopathic spinal arachnoid cyst and syringomyelia. Br J Radiol 60:10231025,1987

9. Dietemann JL, Babin E, Wackenheim A, Bonneville JF, Maitrot D: Percutaneous puncture of spinal cysts in the diagnosis and therapy of syringomyelia and cystic tumors. Neuroradiology 24:59-63, 1982

10. Ditunno JF Jr, Young W, Donovan WH, Creasey G: The international standards booklet for neurological and functional classification of spinal cord injury. Paraplegia 32:70-80, 1994

11. Dohrmann GJ, Rubin JM: Cervical spondylosis and syringomyelia: suboptimal results, incomplete treatment, and the role of intraoperative ultrasound. Clin Neurosurg 34:378-388, 1988

12. Dohrmann GJ, Rubin JM: Intraoperative ultrasound imaging of the spinal cord: syringomyelia, cysts, and tumors-a preliminary report. Surg Neurol 18:395-399, 1982

13. el Masry WS, Biyani A: Incidence, management, and outcome of post-traumatic syringomyelia. In memory of Mr Bernard Williams. J Neurol Neurosurg Psychiatry 60:141-146, 1996

14. Ellertsson AB, Greitz T: The distending force in the production of communicating syringomyelia. Lancet 1:1234, 1970

15. Fehlings MG, Bernstein M: Syringomyelia as a complication of tuberculous meningitis. Can J Neurol Sci 19:84-87, 1992

16. Feigin I, Ogata J, Budzilovich G: Syringomyelia: the role of edema in its pathogenesis. J Neuropathol Exp Neurol 30: 216-232, 1971

17. Fischbein NJ, Dillon WP, Cobbs C, Weinstein PR: The "presyr- 
inx" state: a reversible myelopathic condition that may precede syringomyelia. AJNR Am J Neuroradiol 20:7-20, 1999

18. Foster JB: Neurology of syringomyelia, in Batzdorf U (ed): Syringomyelia: Current Concepts in Diagnosis and Treatment. Baltimore: Williams \& Wilkins, 1991, pp 91-115

19. Gebarski SS, Maynard FW, Gabrielsen TO, Knake JE, Latack JT, Hoff JT: Posttraumatic progressive myelopathy. Clinical and radiologic correlation employing MR imaging, delayed CT metrizamide myelography, and intraoperative sonography. Radiology 157:379-385, 1985

20. Haney A, Stiller J, Zelnik N, Goodwin L: Association of posttraumatic spinal arachnoid cyst and syringomyelia. J Comput Tomogr 9:137-140, 1985

21. Hankinson J: Syringomyelia and the surgeon. Mod Trends Neurol 5:127-148, 1970

22. Harwood-Nash DC, Fitz CR: Myelography and syringohydromyelia in infancy and childhood. Radiology 113:661-669, 1974

23. Heiss JD, Patronas N, DeVroom HL, Shawker T, Ennis R, Kammerer W, et al: Elucidating the pathophysiology of syringomyelia. J Neurosurg 91:553-562, 1999

24. Heiss JD, Suffredini G, Smith R, DeVroom HL, Patronas NJ, Butman JA, et al: Pathophysiology of persistent syringomyelia after decompressive craniocervical surgery. Clinical article. J Neurosurg Spine 13:729-742, 2010

25. Hormigo A, Lobo-Antunes J, Bravo-Marques JM, Marques MS: Syringomyelia secondary to compression of the cervical spinal cord by an extramedullary lymphoma. Neurosurgery 27:834-836, 1990

26. Ikata T, Masaki K, Kashiwaguchi S: Clinical and experimental studies on permeability of tracers in normal spinal cord and syringomyelia. Spine (Phila Pa 1976) 13:737-741, 1988

27. Jinkins JR, Reddy S, Leite CC, Bazan C III, Xiong L: MR of parenchymal spinal cord signal change as a sign of active advancement in clinically progressive posttraumatic syringomyelia. AJNR Am J Neuroradiol 19:177-182, 1998

28. Kaar GF, N'Dow JM, Bashir SH: Cervical spondylotic myelopathy with syringomyelia. Br J Neurosurg 10:413-415, 1996

29. Kakar A, Madan VS, Prakash V: Syringomyelia-a complication of meningitis-case report. Spinal Cord 35:629-631, 1997

30. Kaplan L, Kennedy F: The effect of head posture on the manometrics of the cerebrospinal fluid in cervical lesions: a new diagnostic test. Brain 73:337-345, 1950

31. Klekamp J, Batzdorf U, Samii M, Bothe HW: Treatment of syringomyelia associated with arachnoid scarring caused by arachnoiditis or trauma. J Neurosurg 86:233-240, 1997

32. Kramer KM, Levine AM: Posttraumatic syringomyelia: a review of 21 cases. Clin Orthop Relat Res (334):190-199, 1997

33. Levi AD, Sonntag VK: Management of posttraumatic syringomyelia using an expansile duraplasty. A case report. Spine (Phila Pa 1976) 23:128-132, 1998

34. Levy EI, Heiss JD, Kent MS, Riedel CJ, Oldfield EH: Spinal cord swelling preceding syrinx development. Case report. J Neurosurg 92 (1 Suppl):93-97, 2000

35. Levy LM: MR imaging of cerebrospinal fluid flow and spinal cord motion in neurologic disorders of the spine. Magn Reson Imaging Clin N Am 7:573-587, 1999

36. Levy LM: Toward an understanding of syringomyelia: MR imaging of CSF flow and neuraxis motion. AJNR Am J Neuroradiol 21:45-46, 2000

37. Levy LM, Di Chiro G: MR phase imaging and cerebrospinal fluid flow in the head and spine. Neuroradiology 32:399406, 1990

38. Levy R, Rosenblatt S, Russell E: Percutaneous drainage and serial magnetic resonance imaging in the diagnosis of symptomatic posttraumatic syringomyelia: case report and review of the literature. Neurosurgery 29:429-434, 1991
39. Li KC, Chui MC: Conventional and CT metrizamide myelography in Arnold-Chiari I malformation and syringomyelia. AJNR Am J Neuroradiol 8:11-17, 1987

40. Lonser RR, Butman JA, Oldfield EH: Pathogenesis of tumorassociated syringomyelia demonstrated by peritumoral contrast material leakage. Case illustration. J Neurosurg Spine 4:426, 2006

41. Lucci B, Reverberi S, Greco G: Syringomyelia and syringomielic syndrome by cervical spondylosis. Report on three cases presenting with neurogenic osteoarthropathies. J Neurosurg Sci 25:169-172, 1981

42. Mallucci CL, Stacey RJ, Miles JB, Williams B: Idiopathic syringomyelia and the importance of occult arachnoid webs, pouches and cysts. Br J Neurosurg 11:306-309, 1997

43. Mauer UM, Freude G, Danz B, Kunz U: Cardiac-gated phase-contrast magnetic resonance imaging of cerebrospinal fluid flow in the diagnosis of idiopathic syringomyelia. Neurosurgery 63:1139-1144, 2008

44. McCormick PC, Torres R, Post KD, Stein BM: Intramedullary ependymoma of the spinal cord. J Neurosurg 72:523-532, 1990

45. McLone DG, Siqueira EB: Post-meningitic hydrocephalus and syringomyelia treated with a ventriculoperitoneal shunt. Surg Neurol 6:323-325, 1976

46. Middleton TH, Al-Mefty O, Harkey LH, Parent AD, Fox JL: Syringomyelia after decompressive laminectomy for cervical spondylosis. Surg Neurol 28:458-462, 1987

47. Milhorat TH, Capocelli AL Jr, Kotzen RM, Bolognese P, Heger IM, Cottrell JE: Intramedullary pressure in syringomyelia: clinical and pathophysiological correlates of syrinx distension. Neurosurgery 41:1102-1110, 1997

48. Milhorat TH, Johnson WD, Miller JI: Syrinx shunt to posterior fossa cisterns (syringocisternostomy) for bypassing obstructions of upper cervical theca. J Neurosurg 77:871-874, 1992

49. Milhorat TH, Kotzen RM, Anzil AP: Stenosis of central canal of spinal cord in man: incidence and pathological findings in 232 autopsy cases. J Neurosurg 80:716-722, 1994

50. Oldfield EH, Muraszko K, Shawker TH, Patronas NJ: Pathophysiology of syringomyelia associated with Chiari I malformation of the cerebellar tonsils. Implications for diagnosis and treatment. J Neurosurg 80:3-15, 1994

51. Perrouin-Verbe B, Lenne-Aurier K, Robert R, Auffray-Calvier E, Richard I, Mauduyt de la Grève I, et al: Post-traumatic syringomyelia and post-traumatic spinal canal stenosis: a direct relationship: review of 75 patients with a spinal cord injury. Spinal Cord 36:137-143, 1998

52. Phanthumchinda K, Kaoropthum S: Syringomyelia associated with post-meningitic spinal arachnoiditis due to Candida tropicalis. Postgrad Med J 67:767-769, 1991

53. Pillay PK, Awad IA, Little JR, Hahn JF: Surgical management of syringomyelia: a five year experience in the era of magnetic resonance imaging. Neurol Res 13:3-9, 1991

54. Quencer RM: Needle aspiration of intramedullary and intradural extramedullary masses of the spinal canal. Radiology 134:115-126, 1980

55. Quencer RM, el Gammal T, Cohen G: Syringomyelia associated with intradural extramedullary masses of the spinal canal. AJNR Am J Neuroradiol 7:143-148, 1986

56. Rennels ML, Gregory TF, Blaumanis OR, Fujimoto K, Grady PA: Evidence for a 'paravascular' fluid circulation in the mammalian central nervous system, provided by the rapid distribution of tracer protein throughout the brain from the subarachnoid space. Brain Res 326:47-63, 1985

57. Rossier AB, Foo D, Shillito J, Dyro FM: Posttraumatic cervical syringomyelia. Incidence, clinical presentation, electrophysiological studies, syrinx protein and results of conservative and operative treatment. Brain 108:439-461, 1985

58. Rubin JM: Ultrasonography in spinal cord surgery, in Rubin 
JM, Chandler WF (eds): Ultrasound in Neurosurgery. New York: Raven Press, 1990, pp 107-181

59. Rubin JM, Dohrmann GJ: The spine and spinal cord during neurosurgical operations: real-time ultrasonography. Radiology 155:197-200, 1985

60. Schurch B, Wichmann W, Rossier AB: Post-traumatic syringomyelia (cystic myelopathy): a prospective study of 449 patients with spinal cord injury. J Neurol Neurosurg Psychiatry 60:61-67, 1996

61. Sgouros S, Williams B: A critical appraisal of drainage in syringomyelia. J Neurosurg 82:1-10, 1995

62. Sgouros S, Williams B: Management and outcome of posttraumatic syringomyelia. J Neurosurg 85:197-205, 1996

63. Stoodley MA, Gutschmidt B, Jones NR: Cerebrospinal fluid flow in an animal model of noncommunicating syringomyelia. Neurosurgery 44:1065-1076, 1999

64. Suzuki S, Chiba Y, Hidaka K, Nishimura S, Noji M: [A new operative technique of posttraumatic syringomyelia: thecoperitoneal shunt.] No Shinkei Geka 26:541-546, 1998 (Jpn)

65. Tabor EN, Batzdorf U: Thoracic spinal Pantopaque cyst and associated syrinx resulting in progressive spastic paraparesis: case report. Neurosurgery 39:1040-1042, 1996

66. Tachibana S, Iida H, Yada K: Significance of positive Queckenstedt test in patients with syringomyelia associated with Arnold-Chiari malformations. J Neurosurg 76:67-71, 1992

67. Vassilouthis J, Papandreou A, Anagnostaras S: Thecoperitoneal shunt for post-traumatic syringomyelia. J Neurol Neurosurg Psychiatry 57:755-756, 1994

68. Vassilouthis J, Papandreou A, Anagnostaras S, Pappas J: Thecoperitoneal shunt for syringomyelia: report of three cases. Neurosurgery 33:324-328, 1993
69. Wasserberg J, Marks P, Hardy D: Syringomyelia of the thoracic spinal cord associated with spinal meningiomas. Br J Neurosurg 1:485-488, 1987

70. Wester K, Pedersen PH, Kråkenes J: Spinal cord damage caused by rotation of a T-drain in a patient with syringoperitoneal shunt. Surg Neurol 31:224-227, 1989

71. Williams B: Pathogenesis of syringomyelia, in Batzdorf $U$ (ed): Syringomyelia: Current Concepts in Diagnosis and Treatment. Baltimore: Williams \& Wilkins, 1991, pp 59-90

72. Williams B: Simultaneous cerebral and spinal fluid pressure recordings. 2. Cerebrospinal dissociation with lesions at the foramen magnum. Acta Neurochir (Wien) 59:123-142, 1981

73. Williams B: Syringomyelia. Neurosurg Clin N Am 1:653685,1990

74. Yu YL, Moseley IF: Syringomyelia and cervical spondylosis: a clinicoradiological investigation. Neuroradiology 29:143151,1987

75. Zivin JA: Lateral cervical puncture: an alternative to lumbar puncture. Neurology 28:616-618, 1978

Manuscript submitted December 6, 2011.

Accepted August 8, 2012.

Please include this information when citing this paper: published online September 7, 2012; DOI: 10.3171/2012.8.SPINE111059.

Address correspondence to: John D. Heiss, M.D., Surgical Neurology Branch, National Institutes of Health, 10 Center Drive, 10-5D37, MSC-1414, Bethesda, Maryland 20892-1414. email: heissj@ninds.nih.gov. 